\title{
Au@HgxCd1-xTe core@shell nanorods by sequential aqueous cation exchange for near-infrared photodetectors
}

DOI:

10.1016/j.nanoen.2018.12.030

\section{Document Version}

Accepted author manuscript

Link to publication record in Manchester Research Explorer

\section{Citation for published version (APA):}

Li, X., Iqbal, M. A., Xu, M., Wang, Y. C., Wang, H., Ji, M., Wan, X., Slater, T. J. A., Liu, J., Liu, J., Rong, H., Chen, W., Kershaw, S. V., Haigh, S. J., Rogach, A. L., Xie, L., \& Zhang, J. (2019). Au@Hg Cd Te core@shell nanorods by sequential aqueous cation exchange for near-infrared photodetectors. Nano-Énergy, 57, 57-65. https://doi.org/10.1016/j.nanoen.2018.12.030

\section{Published in:}

Nano Energy

\section{Citing this paper}

Please note that where the full-text provided on Manchester Research Explorer is the Author Accepted Manuscript or Proof version this may differ from the final Published version. If citing, it is advised that you check and use the publisher's definitive version.

\section{General rights}

Copyright and moral rights for the publications made accessible in the Research Explorer are retained by the authors and/or other copyright owners and it is a condition of accessing publications that users recognise and abide by the legal requirements associated with these rights.

\section{Takedown policy}

If you believe that this document breaches copyright please refer to the University of Manchester's Takedown Procedures [http://man.ac.uk/04Y6Bo] or contact uml.scholarlycommunications@manchester.ac.uk providing relevant details, so we can investigate your claim.

\section{OPEN ACCESS}




\section{$\mathrm{Au} @ \mathrm{Hg}_{\mathrm{x}} \mathrm{Cd}_{1-\mathrm{x}} \mathrm{Te}$ Core@Shell Nanorods by Sequential}

\section{Aqueous Cation Exchange for Near-Infrared Photodetectors}

Xinyuan $\mathrm{Li}^{\mathrm{a}}$, Muhammad Ahsan Iqbal ${ }^{\mathrm{b}, \mathrm{d}}$, Meng Xu $\mathrm{u}^{\mathrm{a}}$, Yi-Chi Wang ${ }^{\mathrm{c}}$, Hongzhi Wang ${ }^{\mathrm{a}}$, Muwei Ji ${ }^{\mathrm{e}}$, Xiaodong Wan ${ }^{\mathrm{a}}$, Thomas J. A. Slater, ${ }^{\mathrm{c}, \mathrm{f}}$, Jia Liu ${ }^{\mathrm{a}}$, Jiajia Liu ${ }^{\mathrm{a}}$, Hongpan Rong $^{a}$, Wenxing Chen ${ }^{\mathrm{a}}$, Stephen V. Kershaw ${ }^{\mathrm{g}}$, Sarah J. Haigh ${ }^{\mathrm{c}}$, Andrey L. Rogach ${ }^{\mathrm{g}}$, Liming Xie ${ }^{\mathrm{b}, \mathrm{d}, *}$, Jiatao Zhang ${ }^{\mathrm{a}, *}$

a. Beijing Key Laboratory of Construction-Tailorable Advanced Functional Materials and Green Applications, School of Materials, Beijing Institute of Technology, Beijing 100081, China

E-mail: zhangjt@bit.edu.cn

b. CAS Key Laboratory of Standardization and Measurement for Nanotechnology, CAS Center for Excellence in Nanoscience, National Center for Nanoscience and Technology, Beijing 100190, China.

E-mail: xielm@nanoctr.cn

c. School of Materials, The University of Manchester, Manchester M13 9Pl, U.K.

d. University of Chinese Academy of Sciences, Beijing 100049, P. R. China.

e. Graduate School at Shenzhen, Tsinghua University, Shenzhen 518055, China.

f. Electron Physical Sciences Imaging Centre, Diamond Light Source Ltd., OX11 ODE, U.K.

g. Department of Materials Science and Engineering, City University of Hong Kong, 83 Tat Chee Avenue, Kowloon Tong, Hong Kong S.A.R.

* Corresponding authors.

Keywords: core/shell nanorods, cation exchange synthesis, near-infrared photodetector, crystal phase engineering

Abstract: We have explored the synthesis of $\mathrm{Au} @ \mathrm{Hg}_{\mathrm{x}} \mathrm{Cd}_{1-\mathrm{x}} \mathrm{Te}$ core@ shell nanorods by sequential aqueous cation exchange (ACE) for near-infrared photodetector application. A number of related Au@telluride core/shell nanorod structures were put forwarded, taking advantage of multi-step transformations through a binary and then a ternary phase for the telluride shells. The latter have a high degree of crystallinity thanks to the step-wise ACE method. The use of only trace amounts of $\mathrm{Cd}^{2+}$ coordinated with tri-n-butylphosphine, assisted the phase transformation from an 
amorphous $\mathrm{Ag}_{2} \mathrm{Te}$ shell to a highly crystalline $\mathrm{Ag}_{3} \mathrm{AuTe}_{2}$ shell in the first stage; this was followed by a further cation exchange (CE) step with far higher $\mathrm{Cd}^{2+}$ levels to fabricate a highly crystalline CdTe shell, and with an additional $\mathrm{CE}$ with $\mathrm{Hg}^{2+}$ to convert it to a $\mathrm{Hg}_{\mathrm{x}} \mathrm{Cd}_{1-\mathrm{x}} \mathrm{Te}$ shell. The composition of the shell components and the well-controlled thickness of the shells enabled tunable surface plasmon resonance properties of the Au@telluride nanorods in the NIR region. Utilizing the enhanced NIR absorption, a hybrid photodetector structure of $\mathrm{Au} @ \mathrm{Hg}_{\mathrm{x}} \mathrm{Cd}_{1-\mathrm{x}} \mathrm{Te}$ nanorods on graphene was fabricated, showing visible to NIR (vis-NIR) broadband detection with high photoresponsivity $\left(\sim 10^{6} \mathrm{~A} / \mathrm{W}\right)$.

\section{Introduction}

Metal@semiconductor core/shell hybrid nanostructures with well-defined morphology and a hetero-interface are important both from the point of view of fundamental property investigations and device applications.[1-4] Cation exchange (CE) reactions have been widely utilized as an effective strategy to produce hybrid colloidal semiconductor nanocrystals (NCs) with well-controlled composition and morphologies.[5-16] Morphology retention, a precisely defined interface and regioselectivity are important points in the synthesis of hybrid nanostructures.[10-11, 17-18] Many previously published CE approaches utilized organic solution phase reactions to produce alloy/doped $\mathrm{NCs},[9,13]$ core/shell[1, 14-15] and Janus-like heterostructures.[4, 10-11, 16] Based on the mentioned advantages, CE has been widely applied on the synthesis of NCs for photodetector applications. [8-10] 
Alongside organic CE mthods, aqueous solution-based CE reactions, form an equally important strategy for NC synthesis, and have also been widely reported.[19-21] Aqueous cation exchange (ACE) reactions can be more environmentally friendly and cost effective compared with some organic routes and are of course more suited to cases involving hydrophilic NC surfaces and interfaces.[22-25]

Telluride based NCs have attracted a great deal of attention for their potential applications in quantum devices,[26-29] sensing[30-31] and thermoelectric devices.[32-33] In particular, $\mathrm{CdTe}, \mathrm{HgTe}$ as well as $\mathrm{Hg}_{\mathrm{x}} \mathrm{Cd}_{1-\mathrm{x}} \mathrm{Te} \mathrm{NCs}$ with narrow band gaps are considered as promising candidates for optoelectronic and particularly infrared photodetector materials.[13, 34-38] Compared to well-studied application of isotropic semiconductor QDs or NCs on optoelectronic devices, rod-like structure materials may exhibite extrodinary optical properties due to the polarized properties.[39-40] $\mathrm{Au}$ nanorods (NRs), due to their tailorable surface plasmon resonances (SPR) in the near-infrared (NIR) spectral region,[23, 41-42] offer favorable enhancement of the optical performance when coupled with semicondcutor NCs as hybrid structures.[15, 43-44] The rod-like core-shell NCs with telluride semiconductor shells homogeneously coated on plasmonic Au NRs may exhibit enhanced NIR optoelectronic properties due to their potential coupling of plamons and excitons. In this work, we demonstrate the ACE approach to synthesize a sequence of Au@telluride core/shell NRs at low temperature and characterize their optoelectronic properties at vis-NIR region by fabricating $\mathrm{Au} @ \mathrm{Hg}_{\mathrm{x}} \mathrm{Cd}_{1-\mathrm{x}} \mathrm{Te} \mathrm{NRs}$ on graphene device. For the synthesis part, in the first reaction, using only a trace of 
coordinated $\mathrm{Cd}^{2+}$ a phase transformation was induced in an amorphous $\mathrm{Ag}_{2} \mathrm{Te}$ shell on Au NRs to yield a crystalline $\mathrm{Ag}_{3} \mathrm{AuTe}_{2}$ shell. In the next step, CE with higher $\mathrm{Cd}^{2+}$ concentrations facilitated the formation of a crystalline CdTe shell which was further transformed by $\mathrm{Hg}^{2+}$ treatment to a $\mathrm{Hg}_{\mathrm{x}} \mathrm{Cd}_{1-\mathrm{x}} \mathrm{Te}$ shell, covering the Au NRs uniformly. For photodetector application part, a plasmonic enhanced $\mathrm{Au} @ \mathrm{Hg}_{\mathrm{x}} \mathrm{Cd}_{1-\mathrm{x}} \mathrm{Te} \mathrm{NRs}$ for NIR photodetector applications is demonstrated. Hybrid graphene/Au $@ \mathrm{Hg}_{\mathrm{x}} \mathrm{Cd}_{1-\mathrm{x}} \mathrm{Te}$ NRs device displayed broadband vis-NIR detection and high photoresponsivity, arising from a photogating effect at the NR/graphene interface.[45-49]

\section{Experimental Section}

\subsection{Chemicals}

Te powder $(99.999 \%)$, hydrazine hydrate $(85 \%)$ and $\mathrm{HAuCl}_{4} \cdot 3 \mathrm{H}_{2} \mathrm{O}$ were purchased from Sinopharm Chemical Reagent Co., Ltd. $\mathrm{Cd}\left(\mathrm{NO}_{3}\right)_{2} \bullet 4 \mathrm{H}_{2} \mathrm{O}$ (99.99\%) and hexadecyl trimethyl ammonium chloride (CTAC) were purchased from Aladdin Reagent. Other chemicals were purchased from Beijing Chemical works. All reagents were used directly without further purification.

\subsection{Synthesis of Au@ $\mathrm{Ag}_{2} \mathrm{Te} N R s$}

$\mathrm{Au} @ \mathrm{Ag}$ NRs were prepared following our previous work.[15] $10 \mathrm{~mL}$ of the $\mathrm{Au} @ \mathrm{Ag}$ NRs were mixed with $1.2 \mathrm{~mL}$ of Te precursor (prepared by taking $30 \mathrm{mg} \mathrm{Te}$ powder dissolved in $15 \mathrm{~mL}$ hydrazine hydrate and heating it in an autoclave for $4 \mathrm{~h}$ to form an homogenous solution) drop by drop upon vigorous stirring for $2 \mathrm{~min}$. The resulting solution was aged at $30{ }^{\circ} \mathrm{C}$ in a water bath for $30 \mathrm{~min}$. The resulting product 
was purified by centrifugation at $8000 \mathrm{r} / \mathrm{min}$ for $10 \mathrm{~min}$, and re-dispersed in deionized water.

\subsection{Synthesis of Au@Ag ${ }_{3} A u T e_{2} N R s$}

$1 \mathrm{~mL}$ of $0.2 \mathrm{M}$ hexadecyl trimethyl ammonium bromide (CTAB) solution was added to the $\mathrm{Au} @ \mathrm{Ag}_{2} \mathrm{Te}$ NRs followed by heating the solution to $45{ }^{\circ} \mathrm{C}$ and keeping it at this temperature for $2 \mathrm{~min} .0 .05 \mathrm{~mL}$ of $\mathrm{Cd}\left(\mathrm{NO}_{3}\right)_{2}$ solution $(30 \mathrm{mg} / \mathrm{mL})$ was added, followed by stirring for 2 min. $30 \mu 1$ of tri-n-butylphosphine (TBP) was added under vigorous shaking, and the solution was aged at $45{ }^{\circ} \mathrm{C}$ for $30 \mathrm{~min}$. The resulting product was collected by centrifugation at $8000 \mathrm{r} / \mathrm{min}$ for $10 \mathrm{~min}$, and re-dispersed in deionized water.

\subsection{Synthesis of Au@CdTe NRs}

$1 \mathrm{~mL}$ CTAB solution $(0.2 \mathrm{M})$ was added to the $\mathrm{Au} @ \mathrm{Ag}_{3} \mathrm{AuTe}_{2} \mathrm{NRs}$ upon stirring, and the solution was pre-heated in a $60{ }^{\circ} \mathrm{C}$ water bath for $5 \mathrm{~min} .1 \mathrm{~mL}$ of $30 \mathrm{mg} / \mathrm{mL}$ $\mathrm{Cd}\left(\mathrm{NO}_{3}\right)_{2}$ solution was added and gently stirred for 2 min. $60 \mu \mathrm{l}$ of TBP was added under vigorous shaking for $2 \mathrm{~min}$. The solution was aged in a $60{ }^{\circ} \mathrm{C}$ water bath for $2 \mathrm{~h}$. The resulting product was washed with deionized water, centrifuged at $8000 \mathrm{r} / \mathrm{min}$ for $10 \mathrm{~min}$, and re-dispersed in deionized water. The CdTe NRs were synthesized by similar methods as Au@CdTe NRs except for CE temperature increased to $120{ }^{\circ} \mathrm{C}$ in autoclave for 4 hours.[50-51]

\subsection{Synthesis of Au@ $\mathrm{Hg}_{x} C d_{1-x} \mathrm{Te} N R s$}

0.5 mL CTAC solution $(0.2 \mathrm{M})$ was added to the Au@CdTe NRs upon gentle stirring for $1 \mathrm{~min}$, and $\mathrm{HgCl}_{2}(5 \mathrm{mg} / \mathrm{mL})$ solution was added under vigorous shaking. 
The solution was aged at $25^{\circ} \mathrm{C}$ for $0.5 \mathrm{~h}$, followed by washing with deionized water. The resulting product was collected by centrifugation at $8000 \mathrm{r} / \mathrm{min}$ for $10 \mathrm{~min}$, and re-dispersed in deionized water.

\section{6. ${ }^{31} P$ NMR characterization}

The chosen transition metal salts were dissolved in deuterated methanol $\left(\mathrm{CD}_{3} \mathrm{OD}\right)$ with phosphine. As an example, $0.2 \mathrm{mmol} \mathrm{AgNO}_{3}$ was dissolved in $5 \mathrm{~mL}$ of $\mathrm{CD}_{3} \mathrm{OD}$. After several seconds sonication to ensure complete dissolution, $550 \mu \mathrm{l}$ of the solution were pipetted out, placed into a NMR tube, and mixed with $20 \mu 1$ of TBP.

\subsection{Device Fabrication}

Graphite (Kish) was bought from Covalent Material Corp., Japan. The graphene flakes were mechanically exfoliated onto a silicon substrate with a $300 \mathrm{~nm} \mathrm{SiO} 2$ layer. A copper TEM grid was used as the shadow mask. Electrodes were sputtered with $\mathrm{Au}$ $(80 \mathrm{~nm}) / \mathrm{Ti}(10 \mathrm{~nm}) . \mathrm{Au} @ \mathrm{Hg}_{\mathrm{x}} \mathrm{Cd}_{1-\mathrm{x}} \mathrm{Te}$ NRs were deposited on the graphene by a spray deposition method.[28, 52-53] Briefly, the substrate (cleaned with water) was fixed on a $50{ }^{\circ} \mathrm{C}$ hotplate. An airbrush with adjustable nozzle $(0.2-0.3 \mathrm{~mm})$ was fixed at $10 \mathrm{~cm}$ height over the substrate. The $\mathrm{Au} @ \mathrm{Hg}_{\mathrm{x}} \mathrm{Cd}_{1-\mathrm{x}} \mathrm{Te}$ NRs were loaded in the airbrush and the flow rate was controlled by varying the propellant gas pressure. A ligand exchange process was performed after each 5 passes.[45-46] Specifically, the substrate was soaked in $0.2 \%$ vol EDT/acetonitrile solution for $1 \mathrm{~min}$, followed by washing with ethanol. After 30 passes, the $\mathrm{Au} @ \mathrm{Hg}_{\mathrm{x}} \mathrm{Cd}_{1-\mathrm{x}} \mathrm{Te} \mathrm{NRs}$ covered the graphene without gaps.

\subsection{Photocurrent Measurements}


All the measurements were conducted at room temperature in ambient atmosphere using a Keithley 4200-SCS semiconductor parameter analyzer. A pulsed laser (EXR-4, NKT, Denmark, output wavelength from 540 to $2400 \mathrm{~nm}$ ) was used as the light source with a light spot radius of about $2 \mathrm{~mm}$. Laser wavelength and power attenuation was controlled by series of various filters such as bandpass filters from 550 to $1300 \mathrm{~nm}$ (FKB-VIS-10 and FKB-IR-10, Thorlabs Inc., USA), neutral density filters (GCC-301041, GCC-301061, and GCC-301071, Daheng Optics, China; NENIR10A, NENIR20A, and NENIR30A, Thorlabs Inc., USA). A power meter (PM100A, Thorlabs Inc., USA) was used to measure laser power by selecting a suitable sensor according to the wavelength ranges.

\subsection{Structural Characterization}

XRD patterns were collected using a Bruker D8 X-ray diffractometer (scan rate $6 \%$ min). TEM images were collected using a HITACHI H-7650 transmission electron microscope operating at $80 \mathrm{kV}$. HRTEM images were collected using a FEI Tecnai G2 F20 S-Twin microscope operating at $200 \mathrm{kV}$. Elemental maps shown in Figures 4c, 5b, d and S8 were collected using a FEI Talos 200kV scanning transmission electron microscope, which was equipped with an X-FEG high brightness source and a Super-X EDS detector consisting of four silicon drift detectors (SDDs) with a total collection solid angle of approximately $0.9 \mathrm{sr}$. A convergence angle of $21 \mathrm{mrad}$ and an acceptance inner angle of 55 mrad were used for the annular dark field (ADF) image acquisition. EDS spectrum shown in Figure S4 were collected on a FEI Tecnai G2 F20 S-Twin microscope operating at $200 \mathrm{kV}$, and equipped with an energy dispersive 
X-ray spectroscopy (EDS) detector. UV-vis-NIR spectra were measured on a Shimadzu UV-3600 spectrophotometer. Nuclear Magnetic Resonance (NMR) spectra were measured on a Bruker AVANCE IIITM (400 MHz) NMR spectrometer.

\section{Results and Discussion}

Metal-semiconductor hybrid structures, especially metal-semiconductor core-shell materials, have been well reported their enhanced performance on optical devices due to the plamonic enhancement from metal NCs.[3, 54-55] Besides, NCs with anisotropic structures such as NRs may exhibit extraordinary optical properties due to their arrangements.[39-40] Hence, the metal-semiconductor core-shell NRs with controlled morphology and components may exhibit enhanced optical properties, which could be attractive for photoelectronic device applications. Based on this, we put forwarded a sequential ACE method to synthesis $\mathrm{Au} @ \mathrm{Hg}_{\mathrm{x}} \mathrm{Cd}_{1-\mathrm{x}} \mathrm{Te}$ NRs for such applications. The schematic diagram of the multi-step shell transformations from $\mathrm{Au} @ \mathrm{Ag} \mathrm{NRs}$ to the final product, $\mathrm{Au} @ \mathrm{Hg}_{\mathrm{x}} \mathrm{Cd}_{1-\mathrm{x}} \mathrm{Te} \mathrm{NRs}$, is shown in Figure 1. It is worth mentioning that in the case of Au@CdTe and Au@ $\mathrm{Hg}_{\mathrm{x}} \mathrm{Cd}_{1-\mathrm{x}} \mathrm{Te} \mathrm{NCs}$, a standard CE procedure between $\mathrm{Ag}_{2} \mathrm{Te}$ and $\mathrm{Cd}^{2+}$ in water resulted in poorly crystallized products. To overcome this issue, we employed low concentrations of $\mathrm{Cd}^{2+}$ in an aqueous solution containing a trace of TBP to initialize the phase transformation of the amorphous $\mathrm{Ag}_{2} \mathrm{Te}\left(\mathrm{a}-\mathrm{Ag}_{2} \mathrm{Te}\right)$ shell into a highly crystalline $\mathrm{Ag}_{3} \mathrm{AuTe}_{2}$ layer. The fabrication of the $\mathrm{Ag}_{3} \mathrm{AuTe}_{2}$ intermediate, which has a similar crystal structure to cubic phase CdTe (as shown in the X-ray diffraction (XRD) patterns and transmission 
electron microscopy (TEM) images of Figure 2(II-IV) and Figure S1), made it possible to accomplish further ACE between the $\mathrm{Ag}_{3} \mathrm{AuTe}_{2}$ shell and TBP coordinated $\mathrm{Cd}^{2+}$, which resulted in a highly crystalline CdTe shell and then onward to the $\mathrm{Hg}_{\mathrm{x}} \mathrm{Cd}_{1-\mathrm{x}} \mathrm{Te}$ shell by exchange with $\mathrm{Hg}^{2+}$.

The aqueous synthesis of $\mathrm{Au} @ \mathrm{Ag}_{2}$ Te NRs is achieved by the reaction of $\mathrm{Au} @ \mathrm{Ag}$ NRs with a Te precursor, which was obtained by the hydrothermal treatment of Te powder in hydrazine hydrate aqueous solution. The $\mathrm{Au} @ \mathrm{Ag} \mathrm{NRs}$ and $\mathrm{Au} @ \mathrm{Ag}_{2} \mathrm{Te}$ NRs were characterized by XRD and TEM (Figure 2(I-II)). The TEM image of $\mathrm{Au} @ \mathrm{Ag}_{2} \mathrm{Te}$ NRs (Figure 2(II)) indicates that the $\mathrm{Ag}_{2} \mathrm{Te}$ shell is relatively uniform and maintains the original shape of the Au@Ag NR (Figure 2(I) and S2). The XRD patterns of $\mathrm{Au} @ \mathrm{Ag}$ and $\mathrm{Au} @ \mathrm{Ag}_{2} \mathrm{Te}$ NRs both exhibit four sharp peaks fitting well with the cubic phase Au (JCPDS No. 65-2870), which indicates the stability of the Au core in the telluridation reaction. In addition to the $\mathrm{Au}$ peaks, there is no other extensive peak (Figure 2(II)), which indicates the majority of amorphous $\mathrm{Ag}_{2} \mathrm{Te}$ in the shell. The very low peaks around Au peaks indicate trace amount of monoclinic phase $\mathrm{Ag}_{2} \mathrm{Te}$ (JCPDS No. 65-1104) within the amorphous $\mathrm{Ag}_{2}$ Te shell (Figure S3).

It was previously reported that amorphous $\mathrm{Ag}_{2} \mathrm{Te}$ NPs $(\sim 5 \mathrm{~nm})$ could be successfully converted into CdTe by a phosphine-induced CE reaction in the organic phase.[1] When using TBP coordinated $\mathrm{Cd}^{2+}$ ions in the aqueous phase to react directly with $\mathrm{Au} @ \mathrm{Ag}_{2} \mathrm{Te} \mathrm{NRs}$ at $60{ }^{\circ} \mathrm{C}$, energy dispersive X-ray spectroscopy (EDS) (Figure S4a) demonstrated that some $\mathrm{Cd}(\mathrm{K} \alpha=23.1 \mathrm{keV})$ was present in the resulting NRs. However, a large proportion of $\mathrm{Ag}(\mathrm{K} \alpha=22.2 \mathrm{keV})$ remained in the shell. The 
large amount of the residual $\mathrm{Ag}$ means that the $\mathrm{Ag}^{+}$ions in $\mathrm{Ag}_{2} \mathrm{Te} \mathrm{NCs}$ are only partially replaced by $\mathrm{Cd}^{2+}$; this leads to poor shell crystallinity, as confirmed by TEM and high resolution TEM (HRTEM) images presented in Figures S5a-b, respectively. In support of this observation, the XRD (Figure S5c) shows none of the characteristic peaks for CdTe. Even using a higher reaction temperature of $80^{\circ} \mathrm{C}$, the XRD (Figure S5c) indicates a mixture of cubic $\mathrm{Ag}_{3} \mathrm{AuTe}_{2}$ and hexagonal CdTe with poor crystallinity.

We then mediated the CE kinetics by using TBP coordinated $\mathrm{Cd}^{2+}$. When using a trace amount of $\mathrm{Cd}^{2+}$ ions to react with $\mathrm{Au} @ \mathrm{Ag}_{2} \mathrm{Te} \mathrm{NRs}$ at $45^{\circ} \mathrm{C}$ for $30 \mathrm{~min}$, the amorphous $\mathrm{Ag}_{2}$ Te shell was transferred to crystalline cubic $\mathrm{Ag}_{3} \mathrm{AuTe}_{2}$. Normally, the phosphine-induced $\mathrm{CE}$ reaction happened with a large excess of cations $\left(\mathrm{Cd}^{2+}\right.$ in our system) and reasonable amount of phosphines.[1, 5, 7] The large amount of $\mathrm{Cd}^{2+}$ coordinated with TBP induced the driving force of $\mathrm{CE}$ reactions between $\mathrm{Ag}^{+}$and $\mathrm{Cd}^{2+}$. However, there was only trace amount of Cd-TBP introducing to the reaction system. The trace amount of Cd-TBP provided the driving force for CE reaction, however fully $\mathrm{CE}$ reaction cannot happen due to the lack of reactants. What's more, it has been reported that ion exchange could enable the miscibility of $\mathrm{Au}$ in $\mathrm{Ag}-\mathrm{X}(\mathrm{X}=\mathrm{S}$, Se, Te) system, which is mainly due to the strong affinity and higher bond energy between $\mathrm{Au}$ and X.[56-57] As a result, due to the driving force of CE, the localized $\mathrm{CE}$ reaction at the shell surface breaks the balance of $\mathrm{Ag}^{+}$and $\mathrm{Te}^{2-}$, which causes $\mathrm{Au}$ atoms from the core to diffuse into the shell; this leads to formation of a highly 
crystalline $\mathrm{Ag}_{3} \mathrm{AuTe}_{2}$ shell (Figure 3a). For our system, this phenomenon couldn't be initiated without the introduction of trace amount of $\mathrm{Cd}^{2+}$ (Figure S6).

We tested some other transition metal ions, such as $\mathrm{Zn}^{2+}$ and $\mathrm{Pb}^{2+}$, for their ability to perform the same kind of process, and found out that these two cations cannot perform as efficiently as $\mathrm{Cd}^{2+}$, which may be related to the different coordination ability of $\mathrm{Cd}^{2+}$-phosphines and $\mathrm{Ag}^{+}$-phosphines.[1,7] To support this assumption, and to make comparison to other cations, nuclear magnetic resonance (NMR) was applied to study the coordination abilities of TBP to different cations. The ${ }^{31} \mathrm{P}$ NMR spectra for pure TBP, Ag-TBP, Cd-TBP, Zn-TBP and Pb-TBP are shown in Figure $3 b$. Compared to pure TBP, the Ag-TBP and Cd-TBP coordination shows nearly no shift from 0 to $100 \mathrm{ppm}$. However, $\mathrm{Zn}$-TBP and Pb-TBP show an obvious shift, which means stronger coordination of TBP to $\mathrm{Zn}^{2+}$ and $\mathrm{Pb}^{2+}$. Therefore, when introduced trace amount of these two cations to the system, they would rather coordinate with TBP than participate in the $\mathrm{CE}$ reaction. Hence, $\mathrm{Zn}^{2+}$ and $\mathrm{Pb}^{2+}$ cannot induced the transformation from $\mathrm{Ag}_{2} \mathrm{Te}$ to $\mathrm{Ag}_{3} \mathrm{AuTe}_{2}$ in the aqueous system.

The Au@ $\mathrm{Ag}_{3} \mathrm{AuTe}_{2}$ NRs were characterized by XRD, HRTEM and STEM-EDS analysis. The XRD pattern (Figure 2(III)) matches well with the cubic phase $\mathrm{Ag}_{3} \mathrm{AuTe}_{2}$ (JCPDS No. 65-0444) and Au (JCPDS No. 65-2870), which indicates the high crystallinity of the shell and the maintained majority of the Au core. During the transformation from $\mathrm{Ag}_{2} \mathrm{Te}$ to $\mathrm{Ag}_{3} \mathrm{AuTe}_{2}$, some of the $\mathrm{Au}$ core atoms were outside diffused and the sizes of $\mathrm{Au}$ cores were decreased after formation of crystalline $\mathrm{Ag}_{3} \mathrm{AuTe}_{2}$ shell (Figure 3a and S7). The HRTEM images for amorphous $\mathrm{Au} @ \mathrm{Ag}_{2} \mathrm{Te}$ 
(Figure 4a) and crystalline $\mathrm{Au} @ \mathrm{Ag}_{3} \mathrm{AuTe}_{2}$ NRs (Figure 4b and S8a) confirm the induced crystallization during the $\mathrm{Cd}^{2+}$ initialization process. The associated fast Fourier transformation (FFT) data presented in Figure $4 \mathrm{~b}$ further confirm the presence of $\mathrm{Ag}_{3} \mathrm{AuTe}_{2}$ through identification of (321) and (220) lattice planes. EDS elemental mapping performed in the scanning transmission electron microscope (STEM) (Figure $4 \mathrm{c}$ ) indicate that $\mathrm{Au}, \mathrm{Ag}$ and $\mathrm{Te}$ elements are homogeneously distributed in the shell. Further XPS analysis (Figure S9) indicates the very low percent of $\mathrm{Cd}^{2+}$ located at the surface of $\mathrm{Au} @ \mathrm{Ag}_{3} \mathrm{AuTe}_{2} \mathrm{NRs}$, which means that $\mathrm{Cd}^{2+}$ ions are present in only trace amounts in the localized CE process. The cubic phase of the $\mathrm{Ag}_{3} \mathrm{AuTe}_{2}$ shell has rather similar (body-centered cubic) crystal structure to the face-centered cubic structure of CdTe (or $\mathrm{HgTe}$ ), which is beneficial for the next step of the CE conversion. $[5,10]$

After the trace TBP-Cd ${ }^{2+}$ addition step, the repeated CE between $\mathrm{Au} @ \mathrm{Ag}_{3} \mathrm{AuTe}_{2}$ NRs and TBP coordinated $\mathrm{Cd}^{2+}$ leads to high quality Au@CdTe NRs. The XRD of the latter (Figure 2(IV)) shows no characteristic peak of $\mathrm{Ag}_{3} \mathrm{AuTe}_{2}$ but pure cubic phase CdTe (JCPDS No. 75-2086). Compared to the XRD spectrum of $\mathrm{Au} @ \mathrm{Ag}_{2} \mathrm{Te}$ synthesized by direct CE (Figure S5c), a higher crystallization of the CdTe shell is clearly obtained. The TEM image in Figure 2(IV) shows the monodispersity of as-prepared Au@CdTe NRs, and the HRTEM (Figure 5a and S8b) show the high crystallinity of the CdTe shell, where the measured lattice spacing of $0.372 \mathrm{~nm}$ is assigned to the (111) lattice planes of cubic phase CdTe. The STEM-EDS elemental mapping and line profile results (Figure 5b and S10) further confirm the high quality 
of the CdTe shell. The TEM EDS spectrum (Figure S4b) indicates that a small proportion of $\mathrm{Ag}$ remains ( $\mathrm{Cd}: \mathrm{Ag}=35: 1)$ after the $\mathrm{CE}$ reaction, which may suggest that Ag remains in the structure as a dopant.[7,9]

Cubic bulk CdTe and HgTe have nearly identical lattice constants $\left(\mathrm{a}_{\mathrm{CdTe}}=6.481 \AA\right.$, $\mathrm{a}_{\mathrm{HgTe}}=6.461 \AA$ ) but distinctly different band gaps $\left(\mathrm{E}_{\mathrm{g}, \mathrm{CdTe}}=1.490 \mathrm{eV}, \mathrm{E}_{\mathrm{g}, \mathrm{HgTe}}=-0.261\right.$ eV).[34] As a result, the $\mathrm{Hg}_{\mathrm{x}} \mathrm{Cd}_{1-\mathrm{x}} \mathrm{Te}$ alloy is relatively easy to prepare, and has a composition-tunable band gap covering a wide IR spectral range. Aspects of the $\mathrm{CE}$ reaction between $\mathrm{CdTe}$ and $\mathrm{Hg}_{\mathrm{x}} \mathrm{Cd}_{1-\mathrm{x}} \mathrm{Te}$ quantum dots, particularly concerning the $\mathrm{CE}$ depth from the particle surface and the resulting energy levels, have been reported by many groups.[13, 36, 58] In order to achieve efficient plasmon-exciton coupling further into the NIR region, we carried out the CE reaction between the CdTe shell and $\mathrm{Hg}^{2+}$ to realize highly crystalline $\mathrm{Au} @ \mathrm{Hg}_{\mathrm{x}} \mathrm{Cd}_{1-\mathrm{x}} \mathrm{Te}$ NRs where the shell bandgap was reduced compared to the CdTe shells. The $\mathrm{Au} @ \mathrm{Hg}_{\mathrm{x}} \mathrm{Cd}_{1-\mathrm{x}} \mathrm{Te}$ NR XRD spectrum (Figure 2(V)) shows almost no difference in comparison to the XRD spectrum of Au@CdTe, which is due to the almost identical lattice constants of HgTe (JCPDS No. 75-1553) and CdTe.[10, 34] HRTEM images (Figure 5c and S8c) indicate the high crystallinity of the $\mathrm{Au} @ \mathrm{Hg}_{\mathrm{x}} \mathrm{Cd}_{1-\mathrm{x}} \mathrm{Te} \mathrm{NRs}$; the measured lattice spacings of $0.374 \mathrm{~nm}$ and $0.227 \mathrm{~nm}$ are assigned to (111) and (220) planes of cubic $\mathrm{Hg}_{\mathrm{x}} \mathrm{Cd}_{1-\mathrm{x}} \mathrm{Te}$ respectively by considering the STEM-EDS elemental mapping results (Figure 5d).

It has been widely studied that the morphologies and components of NCs will deeply influence their optical properties. As to analyze the optical properties of NRs with different components, the normalized absorption spectra of the Au@telluride 
NRs at each stage in the series of transformation processes are presented in Figure 6a. With the shell transformation from $\mathrm{Ag}_{2} \mathrm{Te}$ to $\mathrm{Ag}_{3} \mathrm{AuTe}_{2}$ and subsequently to $\mathrm{CdTe}$, the extinction peaks experience an obvious red shift. Au@CdTe NRs have an extinction peak at $1240 \mathrm{~nm}$, while with the addition of $\mathrm{Hg}^{2+}$, the $\mathrm{Au} @ \mathrm{Hg}_{\mathrm{x}} \mathrm{Cd}_{1-\mathrm{x}} \mathrm{Te}$ NRs extinction peak red-shifts to wavelengths between $1563 \mathrm{~nm}\left(\mathrm{Au} @ \mathrm{Hg}_{0.19} \mathrm{Cd}_{0.81} \mathrm{Te}\right.$ NRs) and 1817 nm (Au@ $\left.\mathrm{Hg}_{0.73} \mathrm{Cd}_{0.27} \mathrm{Te} \mathrm{NRs}\right)$. Compared to Au NRs, the absorption spectrum peaks of the as-prepared $\mathrm{Au} @ \mathrm{Hg}_{\mathrm{x}} \mathrm{Cd}_{1-\mathrm{x}} \mathrm{Te}$ core-shell NRs exhibited obvious red shift, which is mainly due to the higher dielectric constants of shell materials.[3, $15,20-21]$ With the increase of $\mathrm{Hg}$ ratio, $\mathrm{Hg}_{\mathrm{x}} \mathrm{Cd}_{1-\mathrm{x}} \mathrm{Te}$ exhibited lower bandgap than pure CdTe, which featured NIR wavelength absorption such as reported QDs or NCs. $[13,27,58]$ When coupling with Au NRs, the as-prepared $\mathrm{Au} @ \mathrm{Hg}_{\mathrm{x}} \mathrm{Cd}_{1-\mathrm{x}} \mathrm{Te} \mathrm{NRs}$ exhibited enhanced absorption in NIR region compared to decoupled $\mathrm{Hg}_{\mathrm{x}} \mathrm{Cd}_{1-\mathrm{x}} \mathrm{Te} \mathrm{NRs}$ with $\mathrm{Au}$ cores over etched (Figure S11). The enhancement is mainly due to the coupling of plasmons from Au cores and excitons from semiconductor shells. Besides, both the shell thickness and the aspect ratio of Au@CdTe NRs can be controlled independently to allow highly tailorable NIR SPR properties of the resulting structures. The extinction spectra of Au@CdTe NRs (shell thickness ranging from 5 $\mathrm{nm}$ to $17 \mathrm{~nm}$, as determined from TEM images shown in Figure S12) are presented in Figure 6b. The absorption peaks of Au@CdTe NRs show an obvious red shift (921 $\mathrm{nm}$ to $1299 \mathrm{~nm}$ ) with an increase in shell thickness.

To demonstrate the application potential of $\mathrm{Au} @ \mathrm{Hg}_{\mathrm{x}} \mathrm{Cd}_{1-\mathrm{x}} \mathrm{Te} \mathrm{NRs}$ which absorb photons in the IR spectral range, a hybrid structure of $\mathrm{Au} @ \mathrm{Hg}_{\mathrm{x}} \mathrm{Cd}_{1-\mathrm{x}} \mathrm{Te} \mathrm{NRs}$ on 
graphene was fabricated (Figure S13). Schematics of the device and the charge transfer mechanism between NRs and graphene are presented in Figure 7. The vis-to-NIR absorption of $\mathrm{Au} @ \mathrm{Hg}_{\mathrm{x}} \mathrm{Cd}_{1-\mathrm{x}} \mathrm{Te} \mathrm{NRs}$ generates charge carriers (electrons and holes); the holes from NRs are transferred to graphene while the electrons are trapped for a time in the NRs.[59-60] Before the eventual electron-hole recombination, the holes in graphene can circle through the device and the external circuit for many times, yielding a high photogain.[45-49] The source-drain current $\left(\mathrm{I}_{\mathrm{sd}}\right)$ in the dark and under light illumination (1200 $\mathrm{nm}$ wavelength) at different source-drain voltages $\left(\mathrm{V}_{\mathrm{sd}}\right)$ for the hybrid graphene/Au@ $\mathrm{Hg}_{\mathrm{x}} \mathrm{Cd}_{1-\mathrm{x}} \mathrm{Te}$ device is depicted in Figure $7 \mathrm{c}$. The device shows a photocurrent of $\sim 13 \mu \mathrm{A}$ without any gating voltage. By applying a gate voltage of $-40 \mathrm{~V}$, the device features a higher photocurrent $(\sim 26 \mu \mathrm{A})$. Gate-dependent photocurrents of the device at different wavelengths are given in Figure S14b. The light intensity-dependent photocurrent is plotted in Figure $7 \mathrm{~d}$ (wavelength at $1200 \mathrm{~nm}$ and $\left.\mathrm{V}_{\mathrm{gs}}=-40 \mathrm{~V}\right)$. Under a low power (49 $\mathrm{nW}$ ) illumination, the device shows a high photoresponsivity of $\sim 3.4 \times 10^{4} \mathrm{~A} / \mathrm{W}$ at $1200 \mathrm{~nm}$. Light intensity-dependent photoresponsivity at wavelengths of 1000 and $1100 \mathrm{~nm}$ are calculated and shown in Figure S14c-e. Responsivities up to $3.3 \times 10^{5} \mathrm{~A} / \mathrm{W}$ (at 1000 $\mathrm{nm}$ ) and $\sim 5.3 \times 10^{5} \mathrm{~A} / \mathrm{W}$ (at $1100 \mathrm{~nm}$ ) are observed.

Wavelength-dependent photoresponsivity of the graphene/Au@ $\mathrm{Hg}_{\mathrm{x}} \mathrm{Cd}_{1-\mathrm{x}} \mathrm{Te} \mathrm{NRs}$ device is shown in Figure 7e. It features a broadband high photoresponse at wavelengths from 550 to $1300 \mathrm{~nm}$. Photoresponsivity (R) and external quantum efficiency (EQE) are critical performance parameters of photodetectors.[61-62] The R 
and EQE of the graphene/Au@ $\mathrm{Hg}_{\mathrm{x}} \mathrm{Cd}_{1-\mathrm{x}} \mathrm{Te}$ NRs photodetector versus the illumination wavelength are shown in Figure $7 \mathrm{f}$ and S15a. The $\mathrm{R}$ is as high as $10^{6} \mathrm{~A} / \mathrm{W}$, and the corresponding EQE exceeds $10^{7} \%$ (Figure S15a). The response time test was also applied on the graphene/Au@ $\mathrm{Hg}_{\mathrm{x}} \mathrm{Cd}_{1-\mathrm{x}} \mathrm{Te}$ NRs photodetector, which exhibited $7.3 \mathrm{~ms}$. (Figure S15b)

To further evaluate the photodetector performance, graphene/ $\mathrm{Hg}_{\mathrm{x}} \mathrm{Cd}_{1-\mathrm{x}} \mathrm{Te} \mathrm{NRs}$ and graphene/Au@ $\mathrm{Ag}_{3} \mathrm{AuTe}_{2} \mathrm{NRs}$ hybrid devices were also fabricated as comparable devices. Compared to graphene/Au@ $\mathrm{Hg}_{\mathrm{x}} \mathrm{Cd}_{1-\mathrm{x}} \mathrm{Te} \mathrm{NRs}$ photodetector, the graphene $/ \mathrm{Hg}_{\mathrm{x}} \mathrm{Cd}_{1-\mathrm{x}} \mathrm{Te} \mathrm{NRs}$ photodetector exhibited similar broadband response but with a lower responsivity in 550-1300 nm (Figure 7f and S17), which indicated the absence of SPR enhancement. Besides, graphene/Au@ $\mathrm{Ag}_{3} \mathrm{AuTe}_{2}$ NRs photodetector exhibited lower photoresponsivity and narrower response wavelength range (cut off at $1200 \mathrm{~nm}$ ) (Figure 7f and S18). Compared to reported photodetectors (Table S2), the graphene/Au@ $\mathrm{Hg}_{\mathrm{x}} \mathrm{Cd}_{1-\mathrm{x}} \mathrm{Te} \mathrm{NRs}$ photodetector exhibited high responsivity and fast response time. Moreover, after the device process, the $\mathrm{Au} @ \mathrm{Hg}_{\mathrm{x}} \mathrm{Cd}_{1-\mathrm{x}} \mathrm{Te}$ NRs nearly maintained the original morphology and components, which is examined by SEM, XRD and XPS (Figure S19).

\section{Conclusions}

In summary, we put forwarded the synthesis of $\mathrm{Au} @ \mathrm{Hg}_{\mathrm{x}} \mathrm{Cd}_{1-\mathrm{x}} \mathrm{Te} \mathrm{NRs}$ by sequential ACE for further application of NIR photodetector. We have demonstrated an ACE approach enabling a serial materials transformation (the robust multiple in situ 
transformations from binary to ternary phase) resulting in the production of high quality Au@telluride NRs. We found that use of the traces of TBP coordinated $\mathrm{Cd}^{2+}$ led to efficient conversion of $\mathrm{Au} @ \mathrm{Ag}_{2} \mathrm{Te}$ (amorphous shell) to $\mathrm{Au} @ \mathrm{Ag}_{3} \mathrm{AuTe}_{2}$ (cubic phase crystalline shell) as a prelude to the further shell transformations. Repeating the CE between Au@ $\mathrm{Ag}_{3} \mathrm{AuTe}_{2} \mathrm{NRs}$ and TBP-coordinated $\mathrm{Cd}^{2+}$ ions, highly crystalline Au@CdTe NRs were produced. As the next step, the ACE between Au@CdTe NRs and $\mathrm{Hg}^{2+}$ enabled highly crystalline $\mathrm{Au} @ \mathrm{Hg}_{\mathrm{x}} \mathrm{Cd}_{1-\mathrm{x}} \mathrm{Te}$ NRs with precisely controlled shell compositions. Benefiting from the tunable optical absorption of the $\mathrm{Au} @ \mathrm{Hg}_{\mathrm{x}} \mathrm{Cd}_{1-\mathrm{x}} \mathrm{Te} \mathrm{NRs}$ in the vis-NIR region (550-1300 nm) combined with the surface plasmon resonance of the $\mathrm{Au}$ NR cores, the hybrid structure of $\mathrm{Au} @ \mathrm{Hg}_{\mathrm{x}} \mathrm{Cd}_{1-\mathrm{x}} \mathrm{Te} \mathrm{NRs}$ on graphene showed a broadband and high photoresponsivity ranging from $10^{3}-10^{7} \mathrm{~A} / \mathrm{W}$.

\section{Appendix A. Supporting information}

Supplementary data associated with this article can be found in the online version at http://dx.doi.org/10.1016/j.nanoen.

\section{Acknowledgements}

This work was supported by the National Natural Science Foundation of China (Grant No. 51631001, 21643003, 51702016, 51501010, 21673058), Fundamental Research Funds for the Central Universities, the Key Research Program of Frontier Sciences of CAS (QYZDB-SSW-SYS031), Beijing Talents Fund (2015000021223ZK17), and the

Talent Introduction Plan of Overseas Top Ranking Professors by the State 
Administration of Foreign Expert Affairs (No. MSBJLG040). S.J.H and Y-C.W acknowledge funding from the Chinese Scholarship Council, the UK Engineering and Physical Sciences Research Council (EP/P009050/1) and European Research Council (Horizon 2020, grant agreement ERC-2016-STG-EvoluTEM-715502).

\section{References}

[1] J. Zhang, Y. Tang, K. Lee, M. Ouyang, Science 327 (2010) 1634-1638.

[2] J. Lee, P. Hernandez, J. Lee, A. O. Govorov, N. A. Kotov, Nat. Mater. 6 (2007) 291.

[3] J. S. Lee, E. V. Shevchenko, D. V. Talapin, J. Am. Chem. Soc. 130 (2008) 9673.

[4] R. Jiang, B. Li, C. Fang, J. Wang, Adv. Mater. 26 (2014) 5274-5309.

[5] D. H. Son, S. M. Hughes, Y. Yin, A. Paul Alivisatos, Science 306 (2004) 1009-1012.

[6] J. M. Hodges, K. Kletetschka, J. L. Fenton, C. G. Read, R. E. Schaak, Angew. Chem. 127 (2015) 8793-8796.

[7] J. Gui, M. Ji, J. Liu, M. Xu, J. Zhang, H. Zhu, Angew. Chem. Int. Ed. 54 (2015) 3683-3687.

[8] B. J. Beberwyck, Y. Surendranath, A. P. Alivisatos, J. Phys. Chem. C. 117 (2013) 19759-19770.

[9] J. Zhang, Q. Di, J. Liu, B. Bai, J. Liu, M. Xu, J. Liu, J. Phys. Chem. Lett. 8 (2017) 4943-4953.

[10] L. De Trizio, L. Manna, Chem. Rev. 116 (2016) 10852-10887. 
[11] J. L. Fenton, B. C. Steimle, R. E. Schaak, Science 360 (2018) 513-517.

[12] A. Sahu, M. S. Kang, A. Kompch, C. Notthoff, A.W. Wills, D. Deng, M.

Winterer, C. D. Frisbie, D. J. Norris, Nano Lett. 12 (2012) 2587.

[13] A. M. Smith, S. Nie, J. Am. Chem. Soc. 133 (2011) 24-26.

[14] Q. Zhao, M. Ji, H. Qian, B. Dai, L. Wang, J. Gui, J. Zhang, M. Ouyang, H. Zhu, Adv. Mater. 26 (2014) 1387-1392.

[15] M. Ji, M. Xu, W. Zhang, Z. Yang, L. Huang, J. Liu, Y. Zhang, L. Gu, Y. Yu, W. Hao, P. An, L. Zheng, H. Zhu, J. Zhang, Adv. Mater. 28 (2016) 3094-3101.

[16] Q. Yuan, D. Liu, N. Zhang, W. Ye, H. Ju, L. Shi, R. Long, J. Zhu, Y. Xiong, Angew. Chem. 129 (2017) 4270-4274.

[17] H. Zhu, Y. Nagaoka, K. Hills-Kimball, R. Tan, L. Yu, Y. Fang, K. Wang, R. Li, Z. Wang, O. Chen, J. Am. Chem. Soc. 139 (2017) 8408-8411.

[18] P. D. Cozzoli, T. Pellegrino, L. Manna, Chem. Soc. Rev. 35 (2006) 1195-1208.

[19] D. Schooss, A. Mews, A. Eychmüller, H. Weller, Phys. Rev. B 49 (1994) 17072.

[20] J. Liu, J. Feng, J. Gui, T. Chen, M. Xu, H. Wang, H. Dong, H. Chen, X. Li, L. Wang, Z. Chen, Z. Yang, J. Liu, W. Hao, Y. Yao, L. Gu, Y. Weng, Y. Huang, X. Duan, J. Zhang, Y. Li, Nano Energy 48 (2018) 44-52.

[21] X. Cheng, J. Liu, J. Feng, E. Zhang, H. Wang, X. Liu, J. Liu, H. Rong, M. Xu, J. Zhang, J. Mater. Chem. A 6 (2018) 11898.

[22] L. Jing, S. V. Kershaw, Y. Li, X. Huang, Y. Li, A. L. Rogach, M. Gao, Chem. Rev. 116 (2016) 10623-10730.

[23] N. Li, P. Zhao, D. Astruc, Angew. Chem. Int. Ed. 53 (2014) 1756-1789. 
[24] V. Lesnyak, N. Gaponik, A. Eychmuller, Chem. Soc. Rev. 42 (2013) 2905-2929.

[25] S. V. Kershaw, L. Jing, X. Huang, M. Gao, A. L. Rogach, Mater. Horiz. 4 (2017) $155-205$.

[26] N. Huo, G. Shuchi, K. Gerasimos, Adv. Mater. 29 (2017) 1606576.

[27] S. Gupta, O. Zhovtiuk, A. Vaneski, Y. C. Lin, W. C. Chou, S. V. Kershaw, A. L. Rogach, Part. Part. Syst. Charact. 30 (2013) 346-354.

[28] M. Chen, H. Lu, N. M. Abdelazim, Y. Zhu, Z. Wang, W. Ren, S. V. Kershaw, A.

L. Rogach, N. Zhao, ACS Nano 11 (2017) 5614-5622.

[29] P. Yu, J. Lin, L. Sun, Q. L. Le, Xu. Yu, G. Gao, C.-H. Hsu, D. Wu, T.-R. Chang, Q. Zeng, F. Liu, Q. J. Wang, H.-T. Jeng, H. Lin, A. Trampert, Z. Shen, K. Suenaga, Z. Liu, Adv. Mater. 29 (2017) 1603991.

[30] Y. S. Rim, S. H. Bae, H. Chen, N. De Marco, Y. Yang, Adv. Mater. 28 (2016) $4415-4440$.

[31] X. Wang, J. Antoszewski, G. Putrino, W. Lei, L. Faraone, B. Mizaikoff, Anal. Chem. 85 (2013) 10648-10652.

[32] M. Safdar, Z. Wang, M. Mirza, F. K. Butt, Y. Wang, L. Sun, J. He, J. Mater. Chem. A. 1 (2013) 1427-1432.

[33] H. Fang, J. H. Bahk, T. Feng, Z. Cheng, A. M. S. Mohammed, X. Wang, X. Ruan, A. Shakouri, Y. Wu, Nano Res. 9 (2016) 117-127.

[34] A. Rogalski, Rep. Prog. Phys. 68 (2005) 2267.

[35] N. Goubet, A. Jagtap, C. Livache, B. Martinez, H. Portalès, X. Z. Xu, R. P. S. M. Lobo, B. Dubertret, E. Lhuillier, J. Am. Chem. Soc. 140 (2018) 5033-5036. 
[36] E. Izquierdo, A. Robin, S. Keuleyan, N. Lequeux, E. Lhuillier, S. Ithurria, J. Am. Chem. Soc. 138 (2016) 10496-10501.

[37] S. Keuleyan, E. Lhuillier, V. Brajuskovic, P. Guyot-Sionnest, Nat. Photonics 5 (2011) 489-493.

[38] P. Geiregat, A. J. Houtepen, L. K. Sagar, I. Infante, F. Zapata, V. Grigel, G. Allan, C. Delerue, D. V. Thourhout, Z. Hens, Nat. Mater. 17 (2018) 35-42.

[39] A. K. Srivastava, W. Zhang, J. Schneider, A. L. Rogach, V. G. Chigrinov, H.-S. Kwok, Adv. Mater. 29 (2017) 1701091.

[40] M. Wang, C. Gao, L. He, Q. Lu, J. Zhang, C. Tang, S. Zorba, Y. Yin, J. Am. Chem. Soc. 135 (2013) 15302-15305.

[41] X. Huang, S. Neretina, M. A. El-Sayed, Adv. Mater. 21 (2009) 4880-4910.

[42] H. Chen, L. Shao, T. Ming, Z. Sun, C. Zhao, B. Yang, J. Wang, Small 6 (2010) 2272-2280.

[43] M. Chen, L. Shao, S. V. Kershaw, H. Yu, J. Wang, A. L. Rogach, N. Zhao, ACS Nano 8 (2014) 8208-8216.

[44] X. Yu, J. Bi, G. Yang, H. Tao, S. Yang, J. Phys. Chem. C 120 (2016) 24533-24541.

[45] G. Konstantatos, M. Badioli, L. Gaudreau, J. Osmond, M. Bernechea, F. P. Garcia de Arquer, F. Gatti, F. H. L. Koppens, Nat. Nanotechnol. 7 (2012) 363-368.

[46] F. H. L. Koppens, T. Mueller, Ph. Avouris, A. C. Ferrari M. S. Vitiello, M. Polini, Nat. Nanotechnol. 9 (2014) 780-793. 
[47] S. Goossens, G. Navickaite, C. Monasterio, S. Gupta, J. J. Piqueras, R. Pérez, G. Burwell, I. Nikitskiy, T. Lasanta, T. Galán, E. Puma, A. Centeno, A. Pesquera, A. Zurutuza, G. Konstantatos, F. Koppens, Nat. Photonics 11 (2017) 366-371.

[48] M. Cui, Y. Guo, Y. Zhu, H. Liu, W. Wen, J. Wu, L. Cheng, Q. Zeng, L. Xie, J. Phys. Chem. C 122 (2018) 7551-7556.

[49] W. Wang, Z. Yan, J. Zhang, J. Lu, H. Qin, Z. Ni, Optica 5 (2018) 27-31.

[50] R. Long, S. Zhou, B. J. Wiley, Y. Xiong, Chem. Soc. Rev. 43 (2014) 6288.

[51] J. Feng, J. Liu, X. Cheng, J. Liu, M. Xu, J. Zhang, Adv. Sci. 5 (2018) 1700376.

[52] F. P. García de Arquer, A. Armin, P. Meredith, E. H. Sargent, Nat. Rev. Mater. 2 (2017) 16100.

[53] M. Chen, H. Yu, S. V. Kershaw, H. Xu, S. Gupta, F. Hetsch, A. L. Rogach, N. Zhao, Adv. Funct. Mater. 24 (2014) 53-59.

[54] H. Wang, J. W. Lim, L. N. Quan, K. Chung, Y. J. Jiang, Y. Ma, D. H. Kim, Adv. Opt. Mater. 6 (2018) 1701397.

[55] B. H. Xie, G. T. Fei, S. H. Xu, X. D. Gao, J. X. Zhang, L. D. Zhang, J. Mater. Chem. C 6 (2018) 1767-1773.

[56] T. Chen, M. Xu, M. Ji, L. Cheng, J. Liu, B. Zhang, J. Zhang, CrystEngComm 18 (2016) 5418-5422.

[57] M. Dalmases, P. Torruella, J. Blanco-Portals, A. Vidal, M. Lopez-Haro, J. J. Calvino, S. Estradé, F. Peiró, A. Figuerola, Chem. Mater. 30 (2018) 6893-6902.

[58] S. V. Kershaw, N. M. Abdelazim, Y. Zhao, A. S. Susha, O. Zhovtiuk, W. Y. Teoh, A. L. Rogach, Chem. Mater. 29 (2017) 2756-2768. 
[59] F. Hetsch, N. Zhao, S. V. Kershaw, A. L. Rogach, Materials Today 16 (2013) $312-325$

[60] D. V. Talapin, J.-S. Lee, M. V. Kovalenko, E. V. Shevchenko, Chem. Rev. 110 (2010) 389-458.

[61] H. Fang, W. Hu, Adv. Sci. 4 (2017) 1700323.

[62] F. Zhuge, Z. Zheng, P. Luo, L. Lv, Y. Huang, H. Li, T. Zhai, Adv. Mater. Technol. 2 (2017) 1700005. 


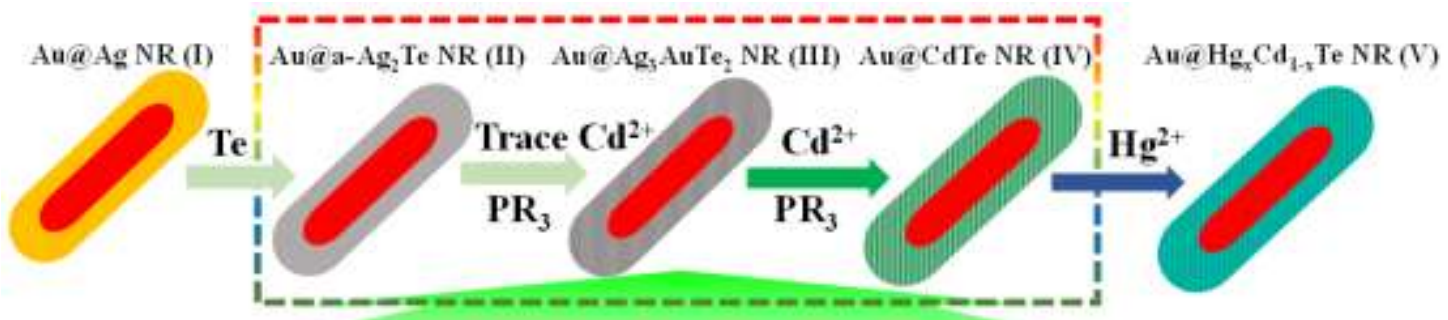

Aqueous Cation Exchange Reactions

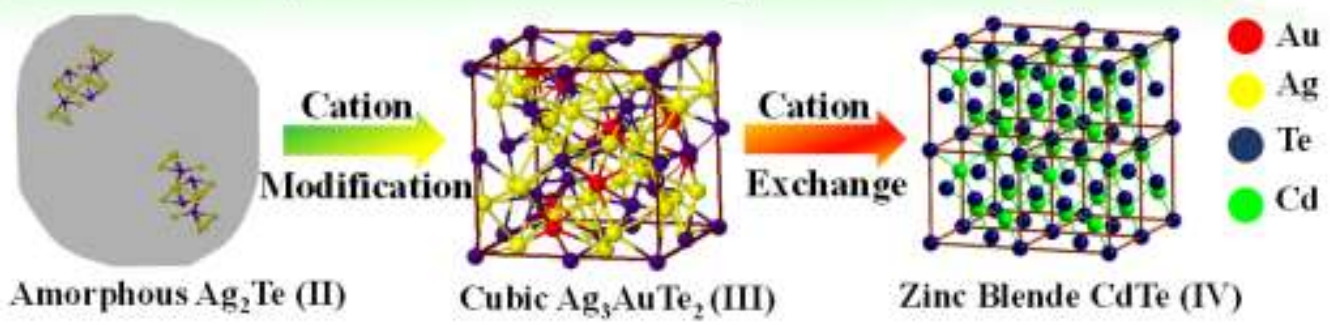

Figure 1. Scheme of aqueous cation-exchange reactions to realize multi-step $\mathrm{Au} @$ telluride NR transformations. 

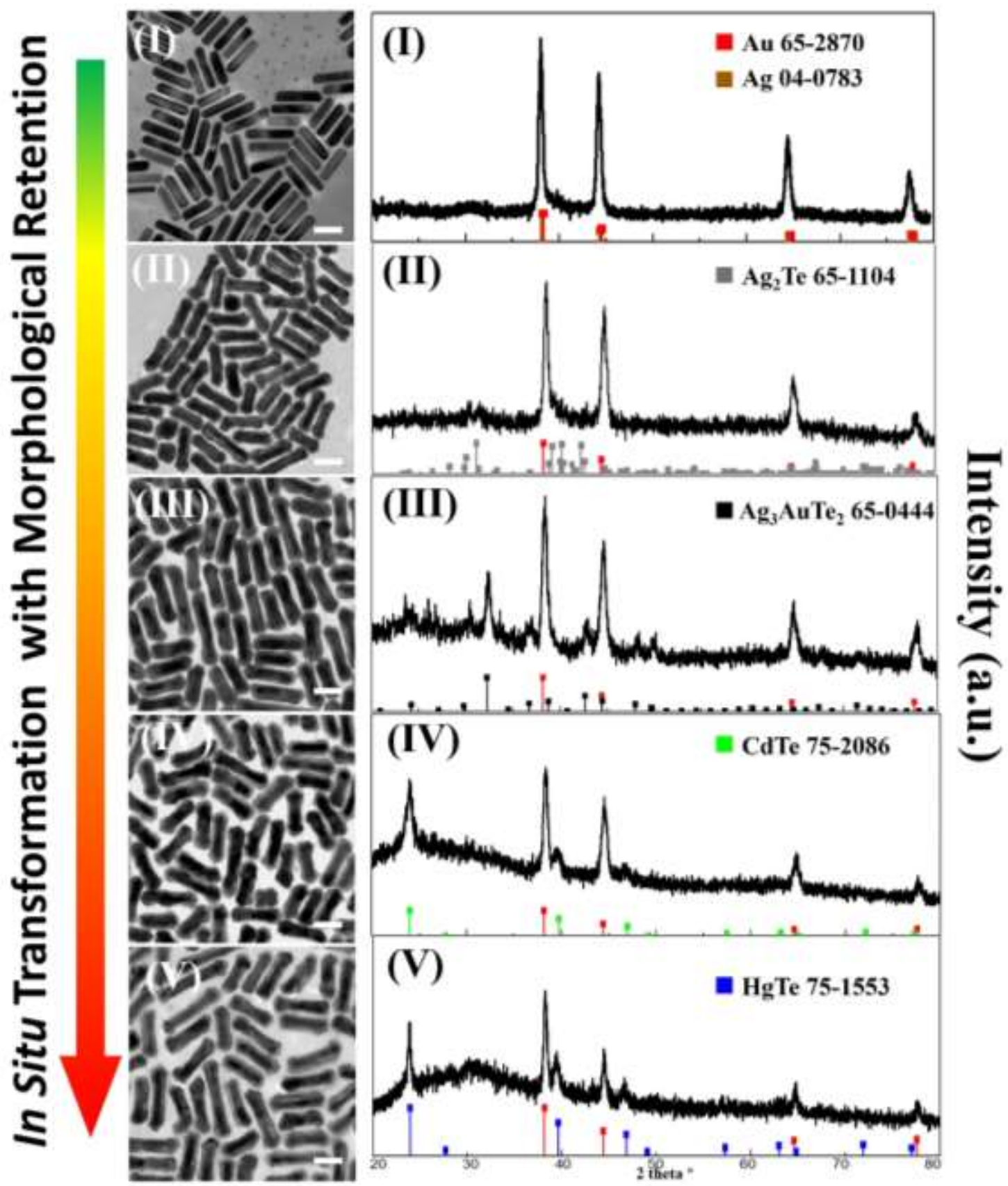

Figure 2. TEM images and X-ray diffraction patterns of (I) $\mathrm{Au} @ \mathrm{Ag} \mathrm{NRs}$, (II) $\mathrm{Au} @ \mathrm{Ag}_{2} \mathrm{Te} \mathrm{NRs}$, (III) $\mathrm{Au} @ \mathrm{Ag}_{3} \mathrm{AuTe}_{2}$ NRs, (IV) Au@CdTe NRs and (V) $\mathrm{Au} @ \mathrm{Hg}_{\mathrm{x}} \mathrm{Cd}_{1-\mathrm{x}} \mathrm{Te}$ NRs. Scale bars are $50 \mathrm{~nm}$ on all TEM images. 


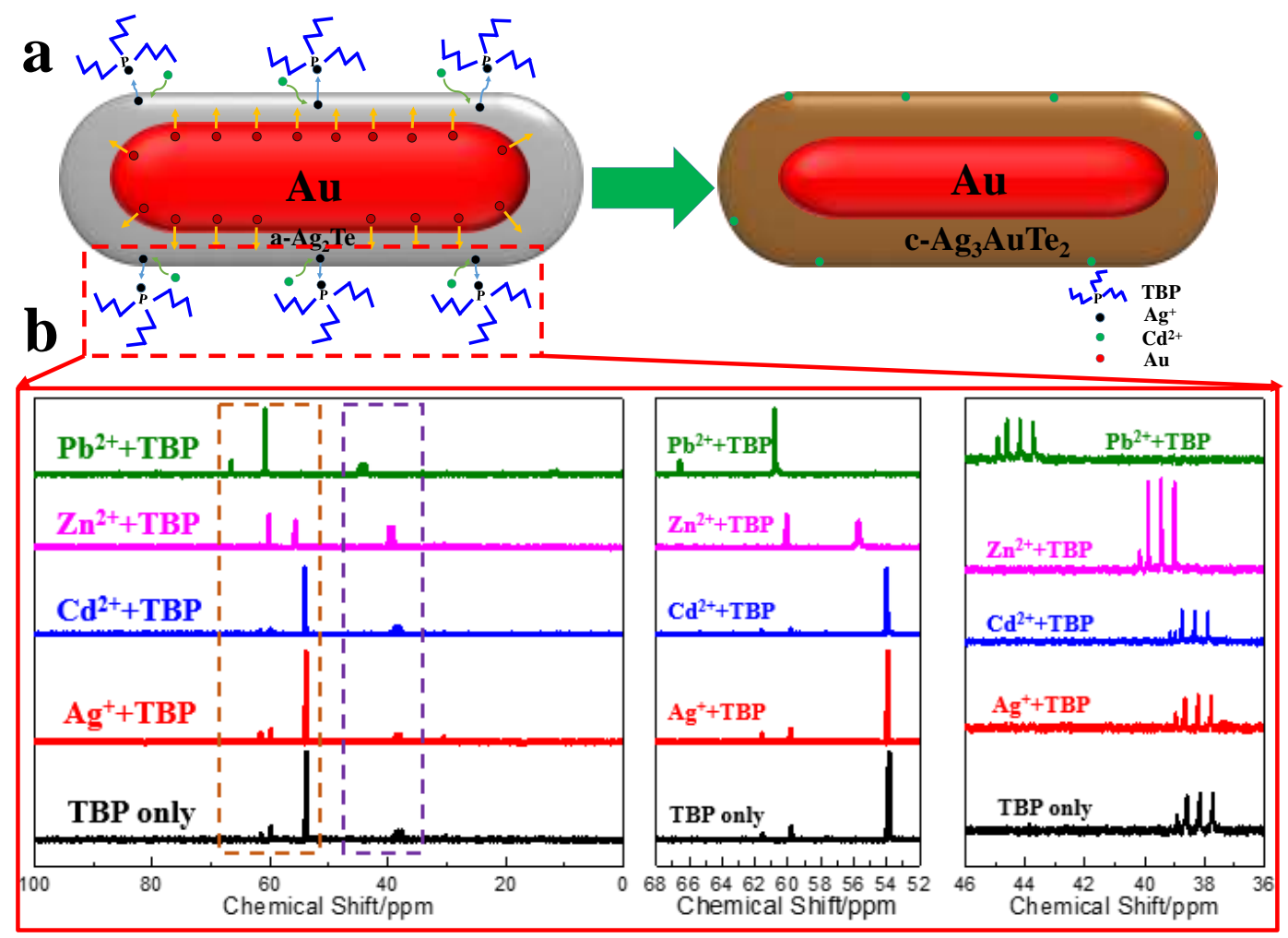

Figure 3. a) Scheme of the cation induced phase transformation process, from the amorphous $\mathrm{Ag}_{2} \mathrm{Te}$ (a-Ag $\mathrm{Ag}_{2} \mathrm{Te}$ ) to cubic $\mathrm{Ag}_{3} \mathrm{AuTe}_{2}\left(\mathrm{c}-\mathrm{Ag}_{3} \mathrm{AuTe}_{2}\right)$. b) NMR spectra of corresponding cations with TBP coordination. 


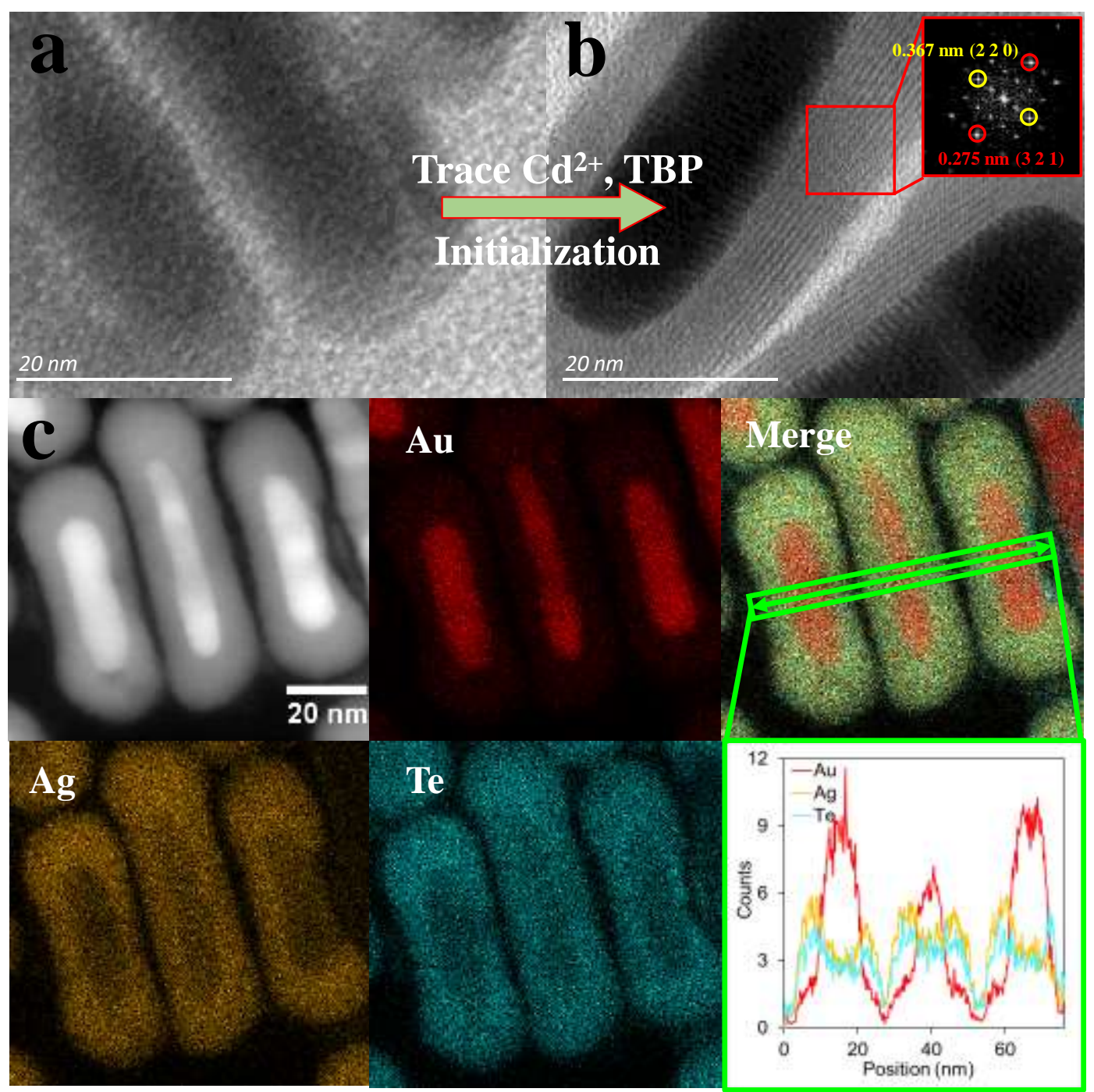

Figure 4. HRTEM images of (a) $\mathrm{Au} @ \mathrm{Ag}_{2} \mathrm{Te}$ and (b) $\mathrm{Au} @ \mathrm{Ag}_{3} \mathrm{AuTe}_{2}$ NRs. The Fourier transform from the shell (inset in b) shows the expected crystal structure of $\mathrm{Ag}_{3} \mathrm{AuTe}_{2}$. c) Dark field STEM image, EDS STEM elemental mapping and compositional profile of $\mathrm{Au} @ \mathrm{Ag}_{3} \mathrm{AuTe}_{2} \mathrm{NRs}$. 


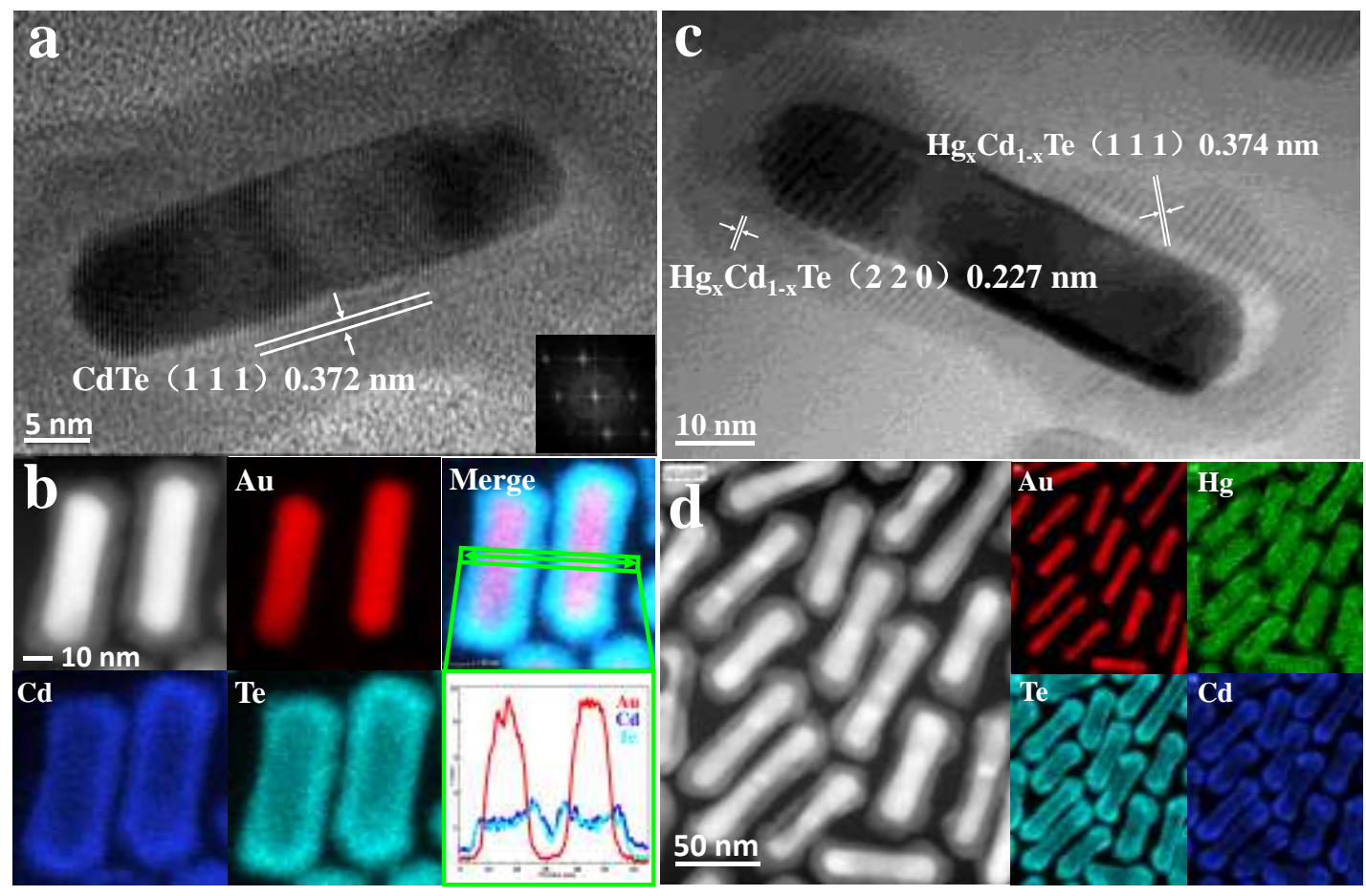

Figure 5. a) HRTEM image of Au@CdTe NRs. Fourier transform in inset demonstrates the high crystallinity of the shell. b) STEM image, EDS elemental mapping and compositional profile of $\mathrm{Au} @ \mathrm{CdTe}$ NRs. c) HRTEM image of $\mathrm{Au} @ \mathrm{Hg}_{\mathrm{x}} \mathrm{Cd}_{1-\mathrm{x}} \mathrm{Te}$ NRs. d) STEM image and EDS elemental mapping of $\mathrm{Au} @ \mathrm{Hg}_{\mathrm{x}} \mathrm{Cd}_{1-\mathrm{x}} \mathrm{Te} \mathrm{NRs}$.
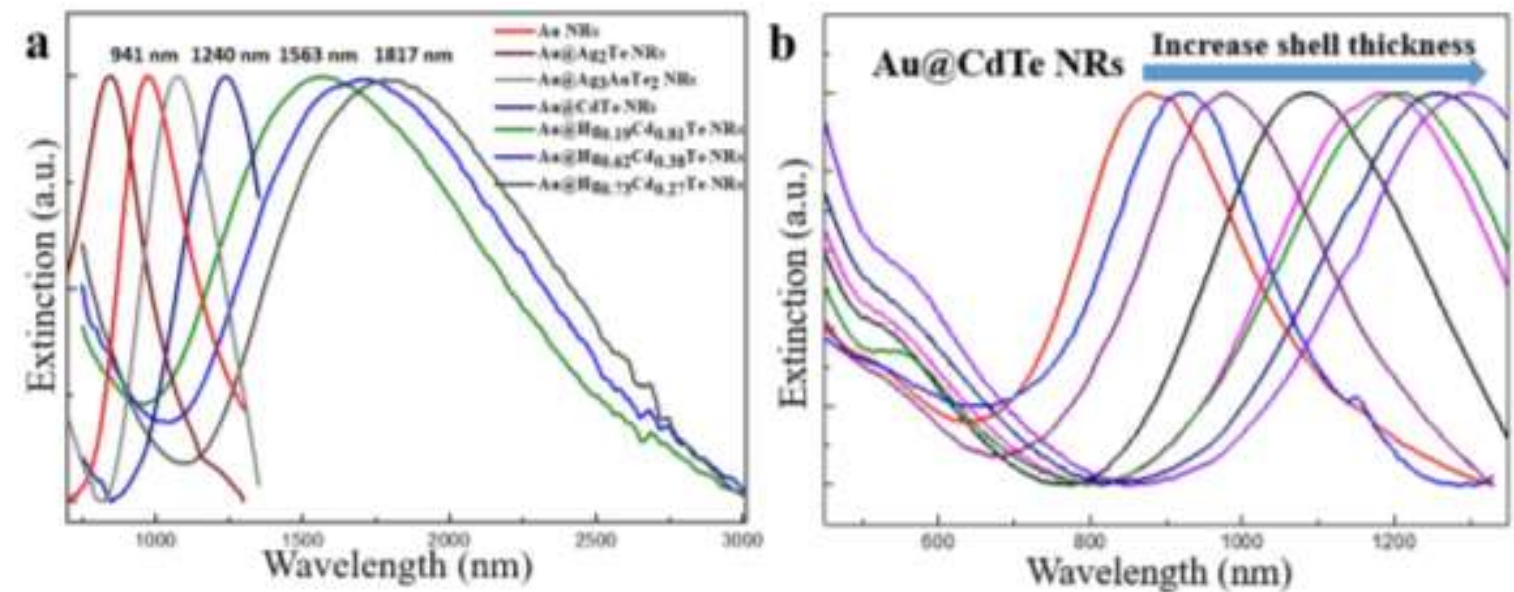

Figure 6. a) Normalized extinction spectra of $\mathrm{Au}, \mathrm{Au} @ \mathrm{Ag}_{2} \mathrm{Te}, \mathrm{Au} @ \mathrm{Ag}_{3} \mathrm{AuTe}_{2}$, $\mathrm{Au} @ \mathrm{CdTe}$, and $\mathrm{Au} @ \mathrm{Hg}_{\mathrm{x}} \mathrm{Cd}_{1-\mathrm{x}} \mathrm{Te}$ NRs. b) Normalized extinction spectra of Au@CdTe NRs with different shell thickness. 


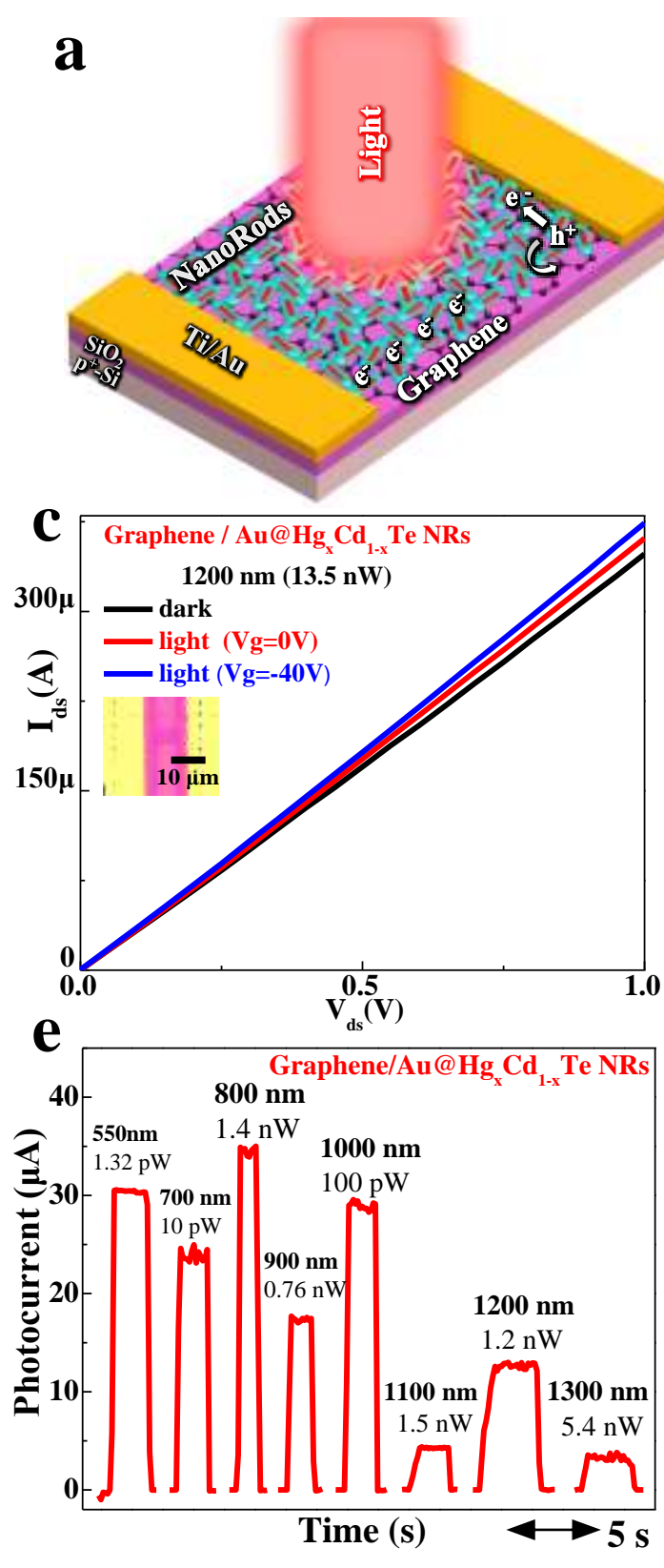

b Charge generation in NanoRods
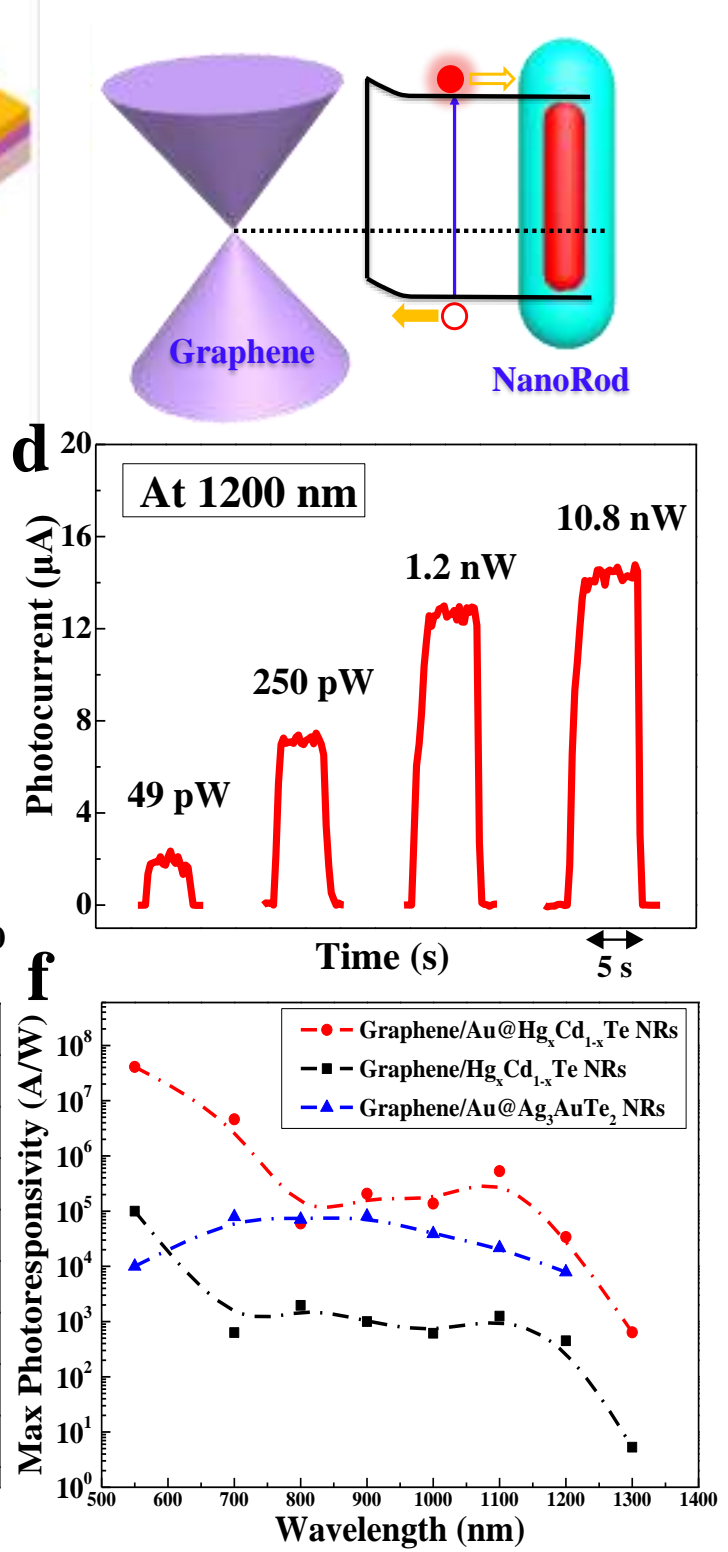

Figure 7. a) Schematic illustration of the hybrid graphene/Au@ $\mathrm{Hg}_{\mathrm{x}} \mathrm{Cd}_{1-\mathrm{x}} \mathrm{Te} \mathrm{NRs}$ photodetector device. b) Photogating mechanism between graphene and $\mathrm{Au} @ \mathrm{Hg}_{\mathrm{x}} \mathrm{Cd}_{1-\mathrm{x}} \mathrm{Te}$ NRs. c) Transfer curves of graphene/Au $@ \mathrm{Hg}_{\mathrm{x}} \mathrm{Cd}_{1-\mathrm{x}} \mathrm{Te}$ NRs with and without light illumination. d) Light intensity-dependent photocurrent (dark current was subtracted) at $1200 \mathrm{~nm}$, e) wavelength-dependent photocurrent at different power intensities and $\mathrm{f}$ ) wavelength dependent photoresponsivity of the graphene/Au@ $\mathrm{Hg}_{\mathrm{x}} \mathrm{Cd}_{1-\mathrm{x}} \mathrm{Te} \quad \mathrm{NRs}, \quad$ graphene/ $\mathrm{Hg}_{\mathrm{x}} \mathrm{Cd}_{1-\mathrm{x}} \mathrm{Te} \quad \mathrm{NRs}$ and graphene/Au@ $\mathrm{Ag}_{3} \mathrm{AuTe}_{2} \mathrm{NRs}$ photodetectors. $\left(\mathrm{V}_{\text {bais }}=4 \mathrm{~V}, \mathrm{~V}_{\mathrm{g}}=-40 \mathrm{~V}\right)$. 
Vitae:

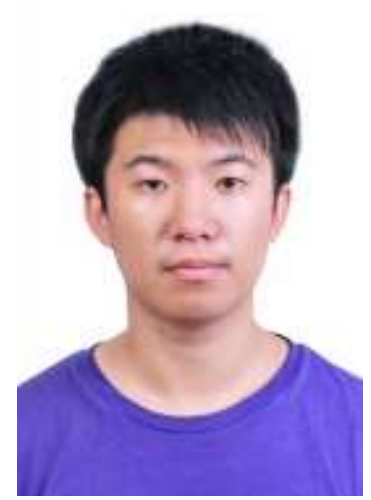

Xinyuan Li received his B.S. degree from Harbin Institute of Technology, China. He revieved his M.S. degree from The University of Manchester, UK. He is currently a Ph.D. student under the supervision of Prof. Jiatao Zhang in Beijing Institute of Technology (BIT), China. His main research interests include the synthesis of semiconductor based hybrid nanostructures and their optoelectronic applications.



Muhammad Ahsan Iqbal received his M.S. degree in Nanotechnology from University of the Punjab, Pakistan. Currently, he is working as a Ph.D. candidate under the supervision of Dr. Liming Xie in the National center for Nanoscience and Technology (NCNST) at University of Chinese Academy of Sciences (UCAS). His current research interests are the two dimensional materials based optoelectronics device applications.

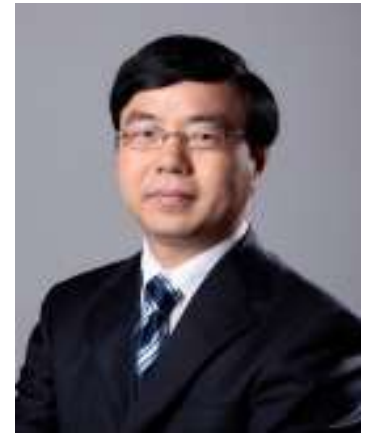

Liming Xie is a Professor in National Center for Nanoscience and Technology, Beijing, China. He received his B.S. degree and Ph.D. degree in physical chemistry 
from Peking University in 2004 and 2009, respectively. During his Ph.D. study, he visited Massachusetts Institute of Technology from 2007 to 2008. He worked at Stanford University as a postdoc from 2009 to 2012. His current research is on two-dimensional materials, including the synthesis, characterization and devices.

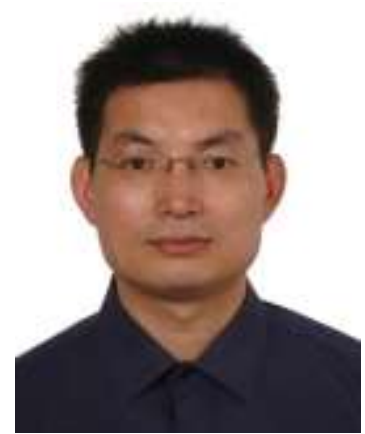

Jiatao Zhang was born in 1975. He earned his Ph.D. in 2006 from chemistry department of Tsinghua University, China. Currently he is Xu Teli Professor in School of Materials and Engineering, Beijing Institute of Technology. He was awarded Excellent Young Scientist foundation of NSFC in 2013. He also serves as the director of Beijing Key Laboratory of Construction-Tailorable Advanced Functional Materials and Green Applications. His current research interest is inorganic chemistry of semiconductor based hybrid nanostructures to possess novel optical, electronic properties for applications in energy conversion and storage, catalysis, optoelectronics and biology. 